\title{
Rifampisine Dirençli Mycobacterium tuberculosis Kompleks İzolatlarının Antitüberküloz İlaç Duyarlıı̆̆ı İcin Sensititre MycoTB Plak Yönteminin Kullanılması
}

\section{Using of the Sensititre MycoTB Plate Method for the Detection of Anti-tuberculous Drug Susceptibility of Rifampin Resistant Mycobacterium tuberculosis Complex Isolates}

\author{
İsmail CEYHAN ${ }_{1}^{11}(I D)^{\prime \prime}$, Sedat VEZIR ${ }^{21}(I D)$, \\ ${ }^{1}$ Balıkesir Üniversitesi Tıp Fakültesi, Tıbbi Mikrobiyoloji Anabilim Dalı, Balıkesir. \\ ${ }^{1}$ Balıkesir University Faculty of Medicine, Department of Medical Microbiology, Balıkesir, Turkey. \\ ${ }^{2}$ Atatürk Göğüs Hastalıkları ve Göğüs Cerrahisi Eğitim ve Araştırma Hastanesi, Ankara. \\ ${ }^{2}$ Atatürk Chest Diseases and Chest Surgery Training and Research Hospital, Ankara, Turkey.
}

Makale Atıfı: Ceyhan i, Vezir S. Rifampisine dirençli Mycobacterium tuberculosis kompleks izolatlarının antitüberküloz ilaç duyarlıı̆ı için Sensititre MycoTB plak yönteminin kullanılması. Mikrobiyol Bul 2020;54(2):211-222.

\section{ÖZ}

Mycobacterium tuberculosis kompleks (MTBK) üyeleri, tüberküloz (TB) hastalığı etkenidir. Klinik MTBK izolatlarında saptanan rifampisin direnci, çok ilaca dirençli tüberküloz (ÇiD-TB) olgularının önemli bir göstergesidir. Bu çalışmada, rifampisine dirençli MTBK izolatlarının ilaç duyarılığını belirlemede Sensititre MycoTB plak yönteminin, rutin kullanıma uygun olup olmadığının değerlendirilmesi amaçlanmışıı. Çaış̧maya, Xpert MTBC/RIF (Cepheid, ABD) test sonucu pozitif rifampisine dirençli 100 MTBK izolatı dahil edilmiştir. Hasta örnekleri, homojenizasyon ve dekontaminasyon işlemi uygulandıktan sonra aside dirençli boyamanın ardından Xpert MTBC/RIF testine alınmıştır. Rifampisine dirençli klinik örnekler, MGIT BACTEC 960 (Becton Dickinson, ABD) sisteminde kültürü yapılarak aside dirençli bakteri (ARB) araştııılmıştır. Kültürden izole edilen ARB ve kord faktör pozitif bakterilere kart testi (MPB64, Capilla TB-Neo, Tauns Laboratories, Inc., Numazu, Japonya) uygulanmış ve MTBK olarak saptanan izolatların Löwenstein-Jensen proporsiyon yöntemi (LIPY) ve Sensititre MycoTB plak (Trek Diagnostic Systems, Cleveland, OH, ABD) yöntemiyle anti-TB ilaç duyarlılık testleri çalışılmıştır. Yöntemler arasında karşılaştırma yapmak amacıyla testler aynı anda çalışıımışır. LJPY, Dünya Sağlık Örgütü tarafından daha önce tarif edildiği gibi, Sensititre MycoTB testi ise üretici firmanın tanımladığı şekilde çalışımış ve değerlendirilmiştir. LJPY'de izoniazid, rifampisin, rifabutin, etambutol, ofloksasin, moksifloksasin, streptomisin, amikasin, kanamisin, sikloserin, etionamid ve p-aminosalisilik asit için final konsantrasyonlar sırasıyla; $0.2 \mu \mathrm{g} / \mathrm{ml}, 40.0 \mu \mathrm{g} / \mathrm{ml}, 20.0 \mu \mathrm{g} / \mathrm{ml}, 2.0 \mu \mathrm{g} / \mathrm{ml}$, $2.0 \mu \mathrm{g} / \mathrm{ml}, 1.0 \mu \mathrm{g} / \mathrm{mL}, 4.0 \mu \mathrm{g} / \mathrm{ml}, 30.0 \mu \mathrm{g} / \mathrm{ml}, 30.0 \mu \mathrm{g} / \mathrm{ml}, 40.0 \mu \mathrm{g} / \mathrm{ml}, 40.0 \mu \mathrm{g} / \mathrm{ml}$ ve $1.0 \mu \mathrm{g} / \mathrm{ml}$ olacak şekilde hazırlanmıştır. Sensititre MycoTB plak yönteminde tüm ilaçlar için 14. günde, LJPY'de ise 28 . ve 42. günlerde sonuç alınmıştır. Çalışmada, Sensititre MycoTB testinin duyarlıık ve özgüllük oranları ile iki test arasındaki kategorik uyum hesaplanmıştır. Sensititre MycoTB plak yönteminin duyarlılığı ve özgüllüğünün 
sırasıyla \%84.4-100 ve \%95.6-100 aralığında olduğu bulunmuştur. Bu çalışmada test edilen ilaçlar için iki yöntem arasındaki kategorik uyum \%92-100 olarak saptanmıştır. Etambutolün en düşük duyarlılık (\%84.4) ve özgüllük (\%95.6) değerlerine sahip ilaç olduğu tespit edilmiştir. İzoniazid, ofloksasin, streptomisin, kanamisin, etionamid ve p-aminosalisilik asit duyarlılıklarının sırasıyla \%98.8, \%90.0, \%94.3, \%87.5, \%91.7 ve \%95.6; rifampisin, rifabutin, moksifloksasin, amikasin, sikloserin duyarlılıklarının ise hepsinde \%100 olduğu saptanmıştır. İzoniazid, rifampisin, rifabutin, ofloksasin, moksifloksasin, amikasin, kanamisin ve sikloserinin özgüllükleri \%100, streptomisin, etionamid ve p-aminosalisilik asidin özgüllükleri ise sırasıyla \%96.9, \%97.4 ve \%98.9 olarak bulunmuştur. Test edilen tüm ilaçlarda kategorik uyum, etambutol (\%92) hariç \%96-100 arasında saptanmıştır. Maliyetinin yüksek olmasına rağmen inkübasyon süresinin kısa olması, kolay uygulanabilmesi, birinci ve ikinci seçenek anti-TB ilaçların duyarlılıklarının aynı anda test edilebilmesi, ilaçların minimum inhibitör konsantrasyonu değerlerinin saptanabilmesi, raf ömrünün uzun olması, yüksek duyarlılık, özgüllük ve kategorik uyum oranları nedeniyle Sensititre MycoTB yönteminin, iş yükü ve çiD-TB olguları fazla laboratuvarlarda kullanılabilecek etkili bir yöntem olduğu sonucuna varılmıştır.

Anahtar kelimeler: Ilaç duyarlılık testi; Mycobacterium tuberculosis kompleks; Löwenstein-Jensen proporsiyon yöntemi; Sensititre MycoTB plak yöntemi.

\section{ABSTRACT}

Members of the Mycobacterium tuberculosis complex (MTBC) are the causative agents of tuberculosis (TB). Rifampin resistance in the clinical isolates of MTBC is an important indicator for multidrug resistant-TB (MDR-TB) cases. In this study, it was aimed to evaluate whether the Sensititre MycoTB plaque method is suitable for the routine use in determining drug susceptibility of rifampin resistant MTBC strains. Xpert MTBC/ RIF positive rifampin resistant 100 MTBC isolates were included in the study. Xpert MTBC/RIF (Cepheid, USA) test were performed after the samples were processed by homogenization and decontamination and acid-fast staining. Rifampin resistant clinical samples were cultured in automated MGIT/BACTEC 960 (Becton Dickinson, USA) system and acid fast bacteria (AFB) were investigated. The anti-TB drug susceptibility tests of all culture positive AFB and cord factor identified as MTBC by using a cart test (MPB64, Capilla TB-Neo, Tauns Laboratories, Inc., Numazu, Japan) were performed with the Löwenstein-Jensen proportion method (LJPM) and Sensititre MycoTB (Trek Diagnostic Systems, Cleveland, OH, USA) methods. For the comparison of the methods used, the tests were performed simultaneously. The standard LJPM was performed according to the previously described procedures by World Health Organization and the Sensititre MycoTB plate method was performed as defined by the manufacturer. The final concentrations of isoniazide, rifampin, rifabutin, ethambutol, ofloxacin, moxifloxacin amikacin, kanamycin, cycloserine, ethionamide and p-aminosalicylic acid in Löwenstein-Jensen media for LJPM were $0.2 \mu \mathrm{g} / \mathrm{ml}, 40.0 \mu \mathrm{g} / \mathrm{ml}, 20.0 \mu \mathrm{g} / \mathrm{ml}$, $2.0 \mu \mathrm{g} / \mathrm{ml}, 2.0 \mu \mathrm{g} / \mathrm{ml}, 1.0 \mu \mathrm{g} / \mathrm{ml}, 4.0 \mu \mathrm{g} / \mathrm{ml}, 30.0 \mu \mathrm{g} / \mathrm{ml}, 30.0 \mu \mathrm{g} / \mathrm{ml}, 40.0 \mu \mathrm{g} / \mathrm{ml}, 40.0 \mu \mathrm{g} / \mathrm{ml}$ and $1.0 \mu \mathrm{g} /$ $\mathrm{ml}$, respectively. The results were obtained in 14 days for all of the drugs in the Sensititre MycoTB plate method and in 28-42 days in the LJPM. In this study, the sensitivity and specificity percentages of the Sensititre MycoTB method and the categorical agreement between the two methods were calculated. The sensitivity and specificity percentages of the Sensititre MycoTB plate method were between 84.4-100\% and 95.6$100 \%$, respectively. The categorical agreements between the two methods were $92-100 \%$ for the drugs tested in the study. Ethambutol was found to have the lowest sensitivity (84.4\%) and specificity (95.6\%). The sensitivities of isoniazide, ofloxacin, streptomycin, kanamycin, ethionamide and p-aminosalicylic acid were $98.8 \%, 90.0 \%, 94.3 \%, 87.5 \%, 91.7 \%$ and $95.6 \%$, respectively, while rifampicin, rifabutin, moxifloxacin, amikacin, cycloserine were calculated as $100 \%$. The specificities of isoniazid, rifampicin, rifabutin, ofloxacin, moxifloxacin, amikacin, kanamycin, and cycloserine were found to be 100\%, streptomycin, ethionamide and p-aminosalicylic specificity were $96.9 \%, 97.4 \%$ and $98.9 \%$ respectively. The categorical agreement was $96-100 \%$ in all tested drugs except ethambutol (92\%). As a result, although the cost is high, owing to the short incubation period, easy to perform, the possibility for evaluating both first and second line anti-TB drugs simultaneously, determination of minimum inhibitory concentration values of the drugs, long shelf life, high sensitivity, specificity and the categorical agreement values, the Sensititre MycoTB method was determined as an effective method that can be used especially in laboratories where the workload and the MDR-TB cases are high.

Keywords: Drug susceptibility test; Mycobacterium tuberculosis complex; Löwenstein-Jensen proportion method; Sensititre MycoTB plate method. 


\section{Giriş}

Tüberküloz (TB) önemli bir halk sağlığı problemi olmaya devam etmektedir ${ }^{1}$. Mycobacterium tuberculosis kompleks (MTBK) türleri, başta akciğer olmak üzere bir çok organ ve dokuda TB hastalığını oluşturabilmektedir². Dünya Sağlık Örgütü (DSÖ), 2017 yılında dünyada 10 milyon yeni TB hastası bildirmiştir. Bu raporda ayrıca 558.000 rifampisine dirençli olgunun yaklaşık \%80'inin, en azından izoniazid ve rifampisine birlikte dirençli olarak tanımlanan, yeni çok ilaca dirençli TB (ÇiD-TB) olduğu belirtilmektedir. ÇiD-TB olgularının tedavi başarısının düşük olduğu, ancak \%55 civarında kaldığı tahmin edilmektedir ${ }^{1}$.

TB olgularının tanı ve tedavisinde çabalar artarak devam etmektedir ${ }^{1,3}$. TB tedavisinde rifampisin, izoniazid, etambutol ve pirazinamid birinci seçenek, ofloksasin, moksifloksasin, amikasin, streptomisin, p-aminosalisik asit, etionamid, sikloserin, kanamisin ise ikinci seçenek ilaçlar olarak verilmektedir. Klasik TB tedavisi, birinci seçenek ilaçlarla sağlanmakta, ancak özellikle ÇiD-TB olgularında ikinci seçenek ilaçlar kritik değer taşımaktadır ${ }^{3}$. Bu nedenle TB tanısı alan olgularda bakterinin tanımlanması ve tanımlanan bakterinin mümkünse en hızlı yöntemle anti-TB ilaç duyarılığının saptanması önem kazanmaktadır ${ }^{3-5}$.

Ulusal Tüberküloz Tanı ve Tedavi Rehberi, ÇiD-TB olgularına hızla tanı konulmasını, rifampisin direnci saptanan izolatların birinci ve ikinci seçenek anti-TB ilaç duyarlılık testlerinin çalışılmasını önermektedir ${ }^{5}$. Son yıllarda Xpert MTBC/RIF sistemi, klinik örneklerden hem MTBK'yı hem de rifampisin direncini dakikalar içinde saptayabilen gerçek-zamanlı polimeraz zincir reaksiyonu (Rt-PCR) mekanizmasına dayanan ticari moleküler bir yöntem olarak kullanılmaya başlanmıştır ${ }^{6}$.

Anti-TB ilaç duyarlılık testlerinde ilk kez standart Löwenstein-Jensen proporsiyon yöntemi (LJPY), Canetti ve arkadaşları ${ }^{7,8}$ tarafından tanımlanmıştır. Daha sonra geliştirilen agar plak yöntemi (APY), altın standart yöntem olarak kabul edilmiştir ${ }^{9}$. Ancak bu yöntemlerin zaman alıcı ve rutinde uygulama zorluklarının bulunması nedeniyle alternatif yeni ve hızlı duyarlılık yöntemlerine olan ihtiyaç $\operatorname{artmıştır~}^{10,11}$. Sensititre MycoTB, bu amaçla geliştirilen ticari duyarlılık test yöntemlerinden biridir.

Sensititre MycoTB plakları, birinci seçenek ilaçlardan izoniazid, rifampisin, etambutol ve ikinci seçenek ilaçlardan ofloksasin, moksifloksasin, streptomisin, etionamid, rifabutin, amikasin, kanamisin, sikloserin ve p-aminosalisik asit olmak üzere 12 liyofilize antiTB ilacın katlı dilüsyonlarını içeren 96 kuyucuktan oluşmaktadır. Plakta ayrıca pozitif kontrol amacıyla iki ilaçsız kuyucuk bulunmaktadır (Şekil 1). Pirazinamid, asidik test koşullarına gereksinim duyduğu için test plaklarında yer almamaktadır ${ }^{10}$. Ayrıca, Sensititre MycoTB plak yönteminin henüz "Food and Drug Administration (FDA)" onayı olmadığından, sadece çalışma amaçlı kullanılmakta olduğu dikkate alınmalıdır. Bu çaış̧mada, MTBK izolatlarının ilaç duyarlılıklarının saptanmasında DSÖ tarafından valide edilen standardize LJPY ile Sensititre MycoTB plak yönteminin uyumunun ve Sensititre 


\begin{tabular}{|c|c|c|c|c|c|c|c|c|c|c|c|c|}
\hline & 1 & 2 & 3 & 4 & 5 & 6 & 7 & 8 & 9 & 10 & 11 & 12 \\
\hline A & $\begin{array}{c}\text { OFL } \\
32\end{array}$ & $\begin{array}{c}\text { MXF } \\
8\end{array}$ & $\begin{array}{l}\text { RIF } \\
16\end{array}$ & $\begin{array}{c}\text { AMI } \\
16\end{array}$ & $\begin{array}{c}\text { STR } \\
32\end{array}$ & $\begin{array}{c}\text { RFB } \\
16\end{array}$ & $\begin{array}{c}\text { PAS } \\
64\end{array}$ & $\begin{array}{c}\text { ETH } \\
40\end{array}$ & $\begin{array}{l}\text { CYC } \\
256\end{array}$ & $\begin{array}{c}\mathrm{INH} \\
4\end{array}$ & $\begin{array}{c}\text { KAN } \\
40\end{array}$ & $\begin{array}{c}\text { EMB } \\
32\end{array}$ \\
\hline$B$ & $\begin{array}{c}\text { OFL } \\
16\end{array}$ & $\begin{array}{c}\text { MXF } \\
4\end{array}$ & $\begin{array}{c}\text { RIF } \\
8\end{array}$ & $\begin{array}{c}\text { AMI } \\
8\end{array}$ & $\begin{array}{c}\text { STR } \\
16\end{array}$ & $\begin{array}{c}\text { RFB } \\
8\end{array}$ & $\begin{array}{c}\text { PAS } \\
32\end{array}$ & $\begin{array}{c}\text { ETH } \\
20\end{array}$ & $\begin{array}{l}\text { CYC } \\
128\end{array}$ & $\begin{array}{c}\mathrm{INH} \\
2\end{array}$ & $\begin{array}{c}\text { KAN } \\
20\end{array}$ & $\begin{array}{c}\text { EMB } \\
16\end{array}$ \\
\hline C & $\begin{array}{c}\text { OFL } \\
8\end{array}$ & $\begin{array}{c}\text { MXF } \\
2\end{array}$ & $\begin{array}{c}\text { RIF } \\
4\end{array}$ & $\begin{array}{c}\mathrm{AMI} \\
4\end{array}$ & $\begin{array}{c}\text { STR } \\
8\end{array}$ & $\begin{array}{c}\text { RFB } \\
4\end{array}$ & $\begin{array}{c}\text { PAS } \\
16\end{array}$ & $\begin{array}{c}\text { ETH } \\
10\end{array}$ & $\begin{array}{c}\text { CYC } \\
64\end{array}$ & $\begin{array}{c}\mathrm{INH} \\
1\end{array}$ & $\begin{array}{c}\text { KAN } \\
10\end{array}$ & $\begin{array}{c}\text { EMB } \\
8\end{array}$ \\
\hline D & $\begin{array}{c}\text { OFL } \\
4\end{array}$ & $\begin{array}{c}\text { MXF } \\
1\end{array}$ & $\begin{array}{c}\text { RIF } \\
2\end{array}$ & $\begin{array}{c}\mathrm{AMI} \\
2\end{array}$ & $\begin{array}{c}\text { STR } \\
4\end{array}$ & $\begin{array}{c}\text { RFB } \\
2\end{array}$ & $\begin{array}{c}\text { PAS } \\
8\end{array}$ & $\begin{array}{c}\text { ETH } \\
5\end{array}$ & $\begin{array}{c}\text { CYC } \\
32\end{array}$ & $\begin{array}{c}\mathrm{INH} \\
0.5\end{array}$ & $\begin{array}{c}\text { KAN } \\
5\end{array}$ & $\begin{array}{c}\mathrm{EMB} \\
4\end{array}$ \\
\hline $\mathrm{E}$ & $\begin{array}{c}\text { OFL } \\
2\end{array}$ & $\begin{array}{c}\text { MXF } \\
0.5\end{array}$ & $\begin{array}{c}\text { RIF } \\
1\end{array}$ & $\begin{array}{c}\mathrm{AMI} \\
1\end{array}$ & $\begin{array}{c}\text { STR } \\
2\end{array}$ & $\begin{array}{c}\text { RFB } \\
1\end{array}$ & $\begin{array}{c}\text { PAS } \\
4\end{array}$ & $\begin{array}{c}\text { ETH } \\
2.5\end{array}$ & $\begin{array}{c}\text { CYC } \\
16\end{array}$ & $\begin{array}{l}\mathrm{INH} \\
0.25\end{array}$ & $\begin{array}{c}\text { KAN } \\
2.5\end{array}$ & $\begin{array}{c}\mathrm{EMB} \\
2\end{array}$ \\
\hline $\mathrm{F}$ & $\begin{array}{c}\text { OFL } \\
1\end{array}$ & $\begin{array}{l}\text { MXF } \\
0.25\end{array}$ & $\begin{array}{l}\text { RIF } \\
0.5\end{array}$ & $\begin{array}{c}\text { AMI } \\
0.5\end{array}$ & $\begin{array}{c}\text { STR } \\
1\end{array}$ & $\begin{array}{c}\text { RFB } \\
0.5\end{array}$ & $\begin{array}{c}\text { PAS } \\
2\end{array}$ & $\begin{array}{c}\text { ETH } \\
1.2\end{array}$ & $\begin{array}{c}\text { CYC } \\
8\end{array}$ & $\begin{array}{l}\mathrm{INH} \\
0.12\end{array}$ & $\begin{array}{c}\text { KAN } \\
1.2\end{array}$ & $\begin{array}{c}\mathrm{EMB} \\
1\end{array}$ \\
\hline$G$ & $\begin{array}{c}\text { OFL } \\
0.5\end{array}$ & $\begin{array}{l}\text { MXF } \\
0.12\end{array}$ & $\begin{array}{c}\text { RIF } \\
0.25\end{array}$ & $\begin{array}{l}\text { AMI } \\
0.25\end{array}$ & $\begin{array}{l}\text { STR } \\
0.5\end{array}$ & $\begin{array}{l}\text { RFB } \\
0.25\end{array}$ & $\begin{array}{c}\text { PAS } \\
1\end{array}$ & $\begin{array}{c}\text { ETH } \\
0.6\end{array}$ & $\begin{array}{c}\text { CYC } \\
4\end{array}$ & $\begin{array}{l}\mathrm{INH} \\
0.06\end{array}$ & $\begin{array}{c}\text { KAN } \\
0.6\end{array}$ & $\begin{array}{c}\text { EMB } \\
0.5\end{array}$ \\
\hline $\mathrm{H}$ & $\begin{array}{c}\text { OFL } \\
0.25\end{array}$ & $\begin{array}{l}\text { MXF } \\
0.06\end{array}$ & $\begin{array}{c}\text { RIF } \\
0.12\end{array}$ & $\begin{array}{l}\text { AMI } \\
0.12\end{array}$ & $\begin{array}{c}\text { STR } \\
0.25\end{array}$ & $\begin{array}{l}\text { RFB } \\
0.12\end{array}$ & $\begin{array}{c}\text { PAS } \\
0.5\end{array}$ & $\begin{array}{c}\text { ETH } \\
0.3\end{array}$ & $\begin{array}{c}\mathrm{CYC} \\
2\end{array}$ & $\begin{array}{l}\text { INH } \\
0.03\end{array}$ & POS & POS \\
\hline
\end{tabular}

Şekil 1. Sensititre MycoTB plağında antibiyotikler ve konsantrasyonlarının $(\mu \mathrm{g} / \mathrm{ml})$ şematik gösterimi (OFL: Ofloksasin, MXF: Moksifloksasin, RIF: Rifampisin, AMI: Amikasin, STR: Streptomisin, RFB: Rifabutin, PAS: p-aminosalisik asit, ETH: Etionamid, CYC: Sikloserin, INH: Izoniazid, KAN: Kanamisin, EMB: Etambutol, POS: Pozitif kontrol).

MycoTB plak yönteminin LJPY'nin yerine kullanılabilecek kadar etkin bir yöntem olup olmadığının belirlenmesi amaçlanmıştır.

\section{GEREÇ ve YÖNTEM}

Çalışmaya rifampisine dirençli 100 MTBK izolatı dahil edildi. Hasta örnekleri, homojenizasyon ve dekontaminasyon işlemi uygulandıktan sonra aside dirençli boyamanın ardından Xpert MTBC/RIF (Cepheid ABD) testine alındı. Test, üretici firmanın önerilerine uygun olarak çalışıldı. Rifampisin direnci bulunan klinik örneklerin BACTEC MGIT 960 (Becton Dickinson, ABD) sisteminde kültürü yapıldı. İzole edilen bakterilerin kord faktörü oluşturup oluşturmadıkları ve aside dirençli bakteri (ARB) özellikleri araştırıldı. ARB ve kord faktör pozitif bakterilere, kart testi (MPB64, Capilla TB-Neo, Tauns Laboratories, Inc., Numazu, Japonya) uygulandı. Kart test ile MTBK olarak tanımlanan bakterilere LJPY ve Sensititre MycoTB (TREK Diagnostic Systems, Cleveland, OH, ABD) plak yöntemiyle aynı anda anti-TB ilaç duyarlık testi uygulandı.

LJPY için önce anti-TB ilaçların stok çözeltileri hazırlandı. İlaçların, rifampisin ve rifabutin (saf etil alkolde) ile ofloksasin ve moksifloksasin (0.1 M NaOH çözeltide) hariç steril distile su içinde çözülerek (A) çözeltileri elde edildi. İzoniazid, rifampisin, rifabutin, ofloksasin, moksifloksasin ve streptomisin için final konsantrasyonları oluşturmaya uygun çalışma (B) çözeltileri hazırlandı. Her bir ilacın (A/B) çözeltilerinden final kon- 
santrasyon oluşturacak miktarları, LJ besiyerlerine ilave edildi ve 17 × $110 \mathrm{~mm}$ burgu kapaklı polistren tüplere 6-7 ml miktarında paylaştırıldı. Daha sonra bu tüpler, $11 \pm$ 0.5 derece yatık vaziyette $85^{\circ} \mathrm{C}^{\prime}$ de $40-45$ dakika pişirildi. LJPY'de izoniazid $(0.2 \mu \mathrm{g} /$ $\mathrm{ml})$, rifampisin $(40.0 \mu \mathrm{g} / \mathrm{ml})$, rifabutin $(20.0 \mu \mathrm{g} / \mathrm{ml})$, etambutol $(2.0 \mu \mathrm{g} / \mathrm{ml})$, ofloksasin $(2.0 \mu \mathrm{g} / \mathrm{ml})$, moksifloksasin $(1.0 \mu \mathrm{g} / \mathrm{ml})$, streptomisin $(4.0 \mu \mathrm{g} / \mathrm{ml})$, amikasin $(30.0 \mu \mathrm{g} /$ $\mathrm{ml})$, kanamisin $(30.0 \mu \mathrm{g} / \mathrm{ml})$, sikloserin $(40.0 \mu \mathrm{g} / \mathrm{ml})$ ve etionamid $(40.0 \mu \mathrm{g} / \mathrm{ml})$ ve p-aminosalisilik asit $(1.0 \mu \mathrm{g} / \mathrm{ml})$ ilaç konsantrasyonları kullanıldı.

Her iki test için çalışmaya en fazla beş haftalık taze kültürler alındı. Çalışmaya başlamadan önce kültürlerin kontaminasyon kontrolü için \%5 koyun kanlı agar (KKA) plaklarına ekimleri yapıldı. KKA besiyerleri, $36 \pm 1^{\circ} \mathrm{C}^{\prime}$ de etüvde 24 saat inkübe edilip üreme gözlenmeyenler çalışmaya dahil edildi. LJPY için standardize bakteri süspansiyonu hazırlandı. Bu süspansiyondan 100 kat sulandırma ile $10^{-2}$ ve $10^{-4}$ lük iki dilüsyon daha yapıldı. $10^{-2 \prime}$ lik dilüsyondan bir kontrol ve ilaçlı besiyerlerine, $10^{-4 \prime}$ lük dilüsyondan ise sadece kontrol amacıyla Löwenstein-Jensen besiyerine $100^{\prime}$ er $\mu$ ekildi. Tüpler, $36 \pm 1^{\circ} \mathrm{C}^{\prime} \mathrm{de}$ inkübe edildi. İlaçlı Löwenstein-Jensen besiyerlerinin kalite kontrolleri, Ulusal Tüberküloz Tanı Rehberine uygun olarak H37Rv (ATCC 27294) suşu ile yapıldı. Sonuçlar, 28. ve 42. günlerde değerlendirildi. $10^{-4}$ 'lük kontrol tüpünde 50 cfu'dan fazla üreme olan testler geçerli olarak kabul edildi. Değerlendirme, $10^{-4}$ lük kontrol tüpüne göre ilaçlı tüplerdeki bakteri üremeleri karşılaştırılarak yapıldı. Kontrol tüpünden daha az üreme içeren ilaçlı tüpler, duyarlı kabul edildi.

Sensititre MycoTB yönteminde çalışma öncesi kit içinde kullanıma hazır bulunan liyofilize antibiyotikli plak, oleik asit-albumin-dekstroz-katalaz (OADC) içerikli 7H9 sıvı besiyeri ve cam boncuk içeren Sensititre saline tween sıvılarının oda sıcaklığına gelmeleri için yaklaşık 30 dakika beklendi. MGIT besiyerinde üremiş taze kültürden 1-2 ml, enjektörle Sensititre saline tween sıvısı içine alındı ve 30 saniye vortekslendi. Türbidite, McFarland $0.5^{\prime}$ e uygun olacak şekilde ayarlandı ve çökmesi için 15 dakika beklendi. Bu bakteri süspansiyonundan $100 \mu \mathrm{l}, 11 \mathrm{ml}$ 'lik 7H9 sıvı besiyerine eklenip 30 saniye vortekslendi. Daha sonra bakteri ekilmiş bu sıvı besiyerinden $100 \mu \mathrm{l}$, çoklu pipet yardımıyla Sensititre MycoTB plağındaki her çukurcuğa ekim yapıldı. Plak üzerine kendinden yapışkanlı özel şeffaf plastik yapıştırıldı ve tüberkülosit dezenfektanla temizlendi. Plaklar, üst üste ikişerli olarak kilitli sızdırmaz plastik poşete konularak $36 \pm 1^{\circ} \mathrm{C}^{\prime}$ de aerobik koşullara sahip etüvde inkübe edildi. Direnç belirlenmesinde izoniazid için $>0.25 \mu \mathrm{g} / \mathrm{ml}$, rifampisin için $>1.0 \mu \mathrm{g} / \mathrm{ml}$, rifabutin için $>0.5 \mu \mathrm{g} / \mathrm{ml}$, etambutol için $>4.0 \mu \mathrm{g} / \mathrm{ml}$, streptomisin için $>2.0 \mu \mathrm{g} / \mathrm{ml}$, amikasin için $>4.0 \mu \mathrm{g} / \mathrm{ml}$, kanamisin için $>5.0 \mu \mathrm{g} / \mathrm{ml}$, ofloksasin için $>2.0 \mu \mathrm{g} / \mathrm{ml}$, moksifloksasin için $>1.0 \mu \mathrm{g} / \mathrm{ml}$, sikloserin için $>32.0 \mu \mathrm{g} / \mathrm{ml}$, etionamid için $>5.0 \mu \mathrm{g} / \mathrm{ml}$ ve $\mathrm{p}$-aminosalisilik asit için $>1.0 \mu \mathrm{g} / \mathrm{ml}$ değerleri esas alındı. Yedinci ve 14. günlerde üreme kontrolü yapıldı. Kontrol kuyucuklarında yeterli üremenin olduğu 14. günde sonuçlar okundu. Üreme kontrolü, üreticinin kılavuzda belirttiği şekilde kuyucukların dibinde bulanıklık veya çökeltinin bulunması durumuna göre manuel olarak değerlendirildi. Plakların manuel olarak kontrol edilmesi aşamasında yanılmayı engelle- 
mek amacıyla okumalar, önce eğitim almış bir teknisyen, daha sonra aynı gün deneyimli uzman tarafından homojen beyaz LED ışık altında yapıldı. Üreme olmayan kuyucuklar, şeffaf olarak kaldı ve minimum inhibitör konsantrasyonu (MiK), üremenin görülmediği en düşük antibiyotik konsantrasyonu olarak kaydedildi.

Sensititre MycoTB plak yönteminde tüm ilaçlar için 14 günde sonuç alındı. LJPY'de ilk okuma 28. günde yapıldı ve kontrol tüpünde yeterli üreme saptanan testler sonuçlandırıldı. Geri kalan tüplerin inkübasyonuna devam edildi ve LJPY'de tüm testler 42. günde tamamlandı.

Veri analizinde, 22.0 IBM SPSS paket programı kullanıldı. Sensititre MycoTB plak yönteminin özgüllük, duyarlılık ve LJPY ile kategorik uyum yüzdeleri hesaplandı. Sonuçlar, \%95 güven aralığında değerlendirilip $\mathrm{p}<0.05$ değeri istatistiksel olarak anlamlı olarak kabul edildi.

\section{BULGULAR}

İzolatların tamamında her iki yöntemle de rifampisin direnci saptanmıştır. Sensititre MycoTB yöntemi ile rifampisin direnci saptananların \%82 ( $n=82)^{\prime}$ sinin aynı zamanda izoniazide de dirençli olduğu görülmüştür. Tek başına rifampisin direnci saptanmamıştır. İzolatların 83'ünde rifabutin, 27'sinde etambutol, 9'unda ofloksasin, 6'sında moksifloksasin, 33'ünde streptomisin, 4'ünde amikasin, 7'sinde kanamisin, 9'unda sikloserin, 20 'sinde etionamid ve 22'sinde p-aminosalisilik asit direnci saptanmıştır. Test edilen 100 MTBK izolatının 17'sinde izoniazid, rifampisin, streptomisin ve etambutole, 11 'inde izoniazid, rifampisin ve streptomisine, 10'unda izoniazid, rifampisin ve etambutole birlikte direnç saptanmıştır. Üç izolatta rifampisin ve izoniazid ile birlikte ofloksasin, 1 izolatta ise kanamisin direnci saptanmıştır. Tek başına etambutol ve rifabutin direnci saptanmamıştır. Etionamid, kanamisin, streptomisin, p-aminosalisilik asit ve sikloserinde diğer ilaçlarla birlikte ve/veya tek ilaç direnci gözlenmiştir. İzolatların 82'sinin ÇiD-TB izolatı, 4'ünün pre-YiD-TB olduğu belirlenmiştir. Çalışmamızda YiD-TB saptanmamıştır.

LJPY esas alındığında, LJPY'nin dirençli, Sensititre MycoTB plak yönteminin duyarlı (yalancı duyarlı) olarak saptadığı sonuçlar, tip-ıl hata (çok büyük hata) olarak tanımlanmış olup 13 farklı izolatta tip-II hata saptanmıştır. Tip-II hata, etambutol için 5, etionamid ve streptomisin için 2 'şer, izoniazid, ofloksasin, kanamisin ve p-aminosalisilik asit için 1'er izolatta görülmüş̧ür.

LJPY'nin duyarlı, Sensititre MycoTB plak yönteminin dirençli (yalancı dirençli) saptadığı sonuçlar, tip-ı hata (büyük hata) olarak tanımlanmış olup 8 farklı izolatta tip-ı hata bulunmuştur. Tip-ı hata saptanan ilaçların dağılımı; etambutolde 3, etionamidde 2 , streptomisinde 2 ve p-aminosalisilik asitte 1 izolat olarak gözlenmiştir.

Sensititre MycoTB plak yöntemiyle elde edilen Mik değerleri dikkate alındığında izoniazid, ofloksasin, moksifloksasin ve streptomisinin LJPY'deki kritik konsantrasyonlarının aynı olduğu, etambutol, p-aminosalisik asit ve sikloserinde farklı olduğu belirlenmiştir. 


\begin{tabular}{|c|c|c|c|}
\hline İlaçlar & LJPY'de KK $(\mu \mathrm{g} / \mathrm{ml})$ & $\begin{array}{c}\text { Sensititre MycoTB } \\
\text { plak yöntemi } \\
\text { konsantrasyon aralığı }\end{array}$ & $\begin{array}{l}\text { Sensititre MycoTB plak yöntemiyle } \\
\text { saptanan konsantrasyon aralığı ve } \\
\text { LJPY'de KK'ye en yakın değerleri }\end{array}$ \\
\hline INH & 0.2 & $0.03-4.0$ & $0.25(<0.03-4)$ \\
\hline RIF & 40.0 & $0.12-16.0$ & UD $(2.0-16)$ \\
\hline RFB & $20.0^{*}$ & $0.12-16.0$ & UD $(<0.12-16)$ \\
\hline EMB & 2.0 & $0.5-32.0$ & $5(0.5-32)$ \\
\hline OFL & 2.0 & $0.25-32.0$ & $2(0.25-4)$ \\
\hline MXF & $1.0^{*}$ & $0.06-8.0$ & $1.0(0.06-4)$ \\
\hline STR & 4.0 & $0.25-32.0$ & $4(0.25-32)$ \\
\hline AMI & 30.0 & $0.12-16.0$ & UD (0.12-4) \\
\hline KAN & 30.0 & $0.6-40.0$ & UD (0.6-10) \\
\hline CYC & 40.0 & $2.0-256.0$ & $32(4.0-32)$ \\
\hline ETH & 40.0 & $0.3-40.0$ & UD $(<0.3-40)$ \\
\hline PAS & 1.0 & $0.5-64.0$ & $2(0.5-8)$ \\
\hline \multicolumn{4}{|c|}{$\begin{array}{l}\text { INH: İzoniazid, RIF: Rifampisin, RFB: Rifabutin, EMB: Etambutol, OFL: Ofloksasin, MXF: Moksifloksasin, } \\
\text { STR: Streptomisin, AMI: Amikasin, KAN: Kanamisin, CYC: Sikloserin, ETH: Etionamid, PAS: p-aminosalisik asit, } \\
\text { UD: Uygun değil. }\end{array}$} \\
\hline
\end{tabular}

Rifampisin, rifabutin, amikasin, kanamisin ve etionamidde MiK değerlerine karşılık gelen değerler uygun bulunmamıştır. Tablo I'de LJPY'nin kritik konsantrasyonları, Sensititre MycoTB ile saptanan ilaç MiK değer aralıkları ve LJPY'ye karşılık gelen konsantrasyonları gösterilmiştir.

Sensititre MycoTB plak yöntemin duyarlılığı \%84.4-100 ve özgüllüğü \%95.6-100, iki yöntem arasındaki kategorik uyum \%92.0-100 aralığında saptanmıştır. Etambutolün en düşük duyarlılık (\%84.4) ve özgüllük (\%95.6) değerlerine sahip ilaç olduğu görülmüştür. İzoniazid, ofloksasin, streptomisin, kanamisin, etionamid ve p-aminosalisilik asidin duyarlııkları, sırasıyla \%98.8, \%90.0, \%94.3, \%87.5, \%91.7 ve \%95.6 iken, rifampisin, rifabutin, moksifloksasin, amikasin ve sikloserinin \%100 olarak hesap edilmiştir. İzoniazid, rifampisin, rifabutin, ofloksasin, moksifloksasin, amikasin, kanamisin ve sikloserinin özgüllükleri \%100, streptomisin, etionamid ve p-aminosalisilik asidin özgüllükleri ise sırasıyla \%96.9, \%97.4 ve \%98.9 olarak bulunmuştur. Test edilen tüm ilaçlarda kategorik uyum etambutol (\%92) hariç, \%96-100 arasında saptanmıştır. Çalışma sonucunda izolatların 82'sinin her iki yöntemle de ÇiD-TB oldukları bulunmuştur. Sonuçlar Tablo II'de sunulmuştur. 


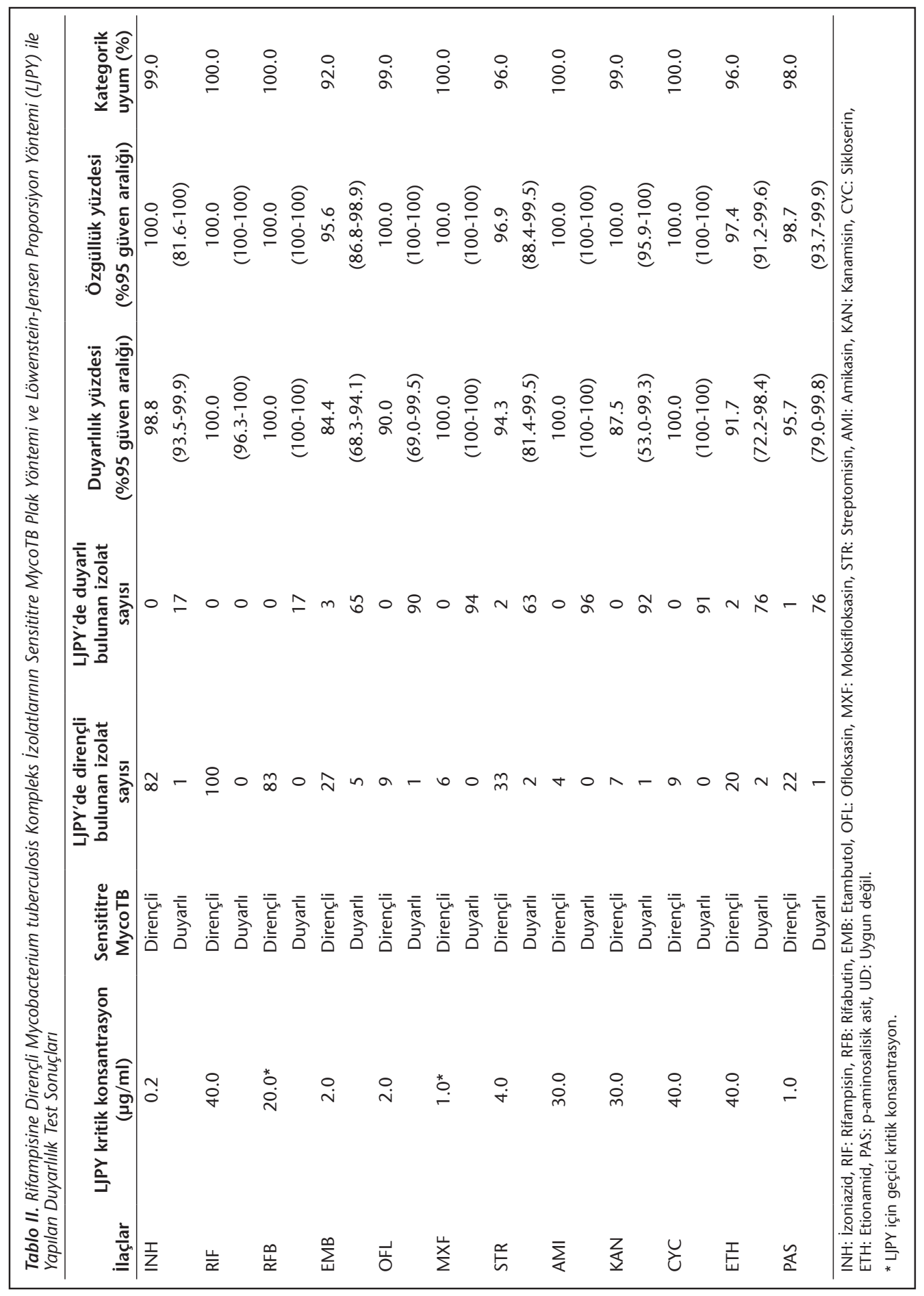




\section{TARTIŞMA}

Dünyada yaklaşık 10 milyon TB olgusunun bulunduğu tahmin edilmektedir. Hastalık nedeniyle en az 300.000'i HIV/AIDS'li olmak üzere 1.6 milyon kişi hayatını kaybetmektedir. ÇiD-TB olgularına en kısa sürede tanı konulması ve uygun ilaçlarla tedavi edilmesi, hastalığın kontrol altına alınması açısından çok önemlidir. Çünkü ÇiD-TB, sadece HIV/ AIDS birlikteliğinde değil, tüm TB olgularında morbidite ve mortaliteyi önemli ölçüde arttırmakta, tedavi süresini uzatmakta, maliyetlerin ve ilaç yan etkisinin artmasına neden olmaktadır ${ }^{1}$. Bu nedenle TB olgularından izole edilen MTBK izolatlarının hızlı, kolay ve standart yöntemlerle laboratuvar tanısı ve ilaç duyarlılıklarının yapılmasına olan ihtiyaç giderek artmaktadır3,10. Ulusal Tüberküloz Tanı ve Tedavi Rehberinde özellikle ÇiD-TB olgularının hızlı tanısı ve tedavisinin önemi vurgulanmaktadır ${ }^{5}$. Altın standart olarak kabul edilen APY uygulanması zor, zaman alıcı ve çoğu kez tekrarlanması gerektiğinden rutin kullanıma uygun bulunmamıştır ${ }^{10}$. LJPY, DSÖ tarafından tarif edilen standart bir yöntemdir 3,7,8,11. Ancak en önemli dezavantajı, 4-6 hafta gibi çok geç sürede sonuçlanmasıdır ${ }^{8,11}$. Sensititre MycoTB plak yöntemi ise pirazinamid hariç, birinci ve ikinci seçenek anti-TB ilaçların duyarlılıklarını birlikte test edebilmesi, kolay uygulanabilmesi ve değerlendirilebilmesi ve sonuç alma süresinin kısa olması gibi avantajları bakımından son yıllarda çalışılmaya başlanmıştır ${ }^{10-14}$.

Çalışmamızda LJPY'de rifabutin ve moksifloksasin hariç, daha önce önerilen kritik konsantrasyonlar kullanılmıştır ${ }^{3}$. Bu iki ilaç için Löwenstein-Jensen'de kritik konsantrasyon belirlenmemiştir. Bu nedenle literatür araştırılmış moksifloksasin için Yu ve arkadaşlarının yaptıkları çalışmadaki kritik konsantrasyona yakın bir değer olarak $1.0 \mu \mathrm{g} / \mathrm{ml}$ 'nin, rifabutin için ise yine aynı çalışmada saptanan değerin $(20 \mu \mathrm{g} / \mathrm{ml})$ çalışılması uygun bulunmuştur ${ }^{11}$. Anti-TB ilaç direncinin belirlenmesinde Sensititre MycoTB plak testi için Lee ve arkadaşlarının çalışması ${ }^{12}$, LJPY için ise rifabutin ve moksifloksasin hariç daha önce verilen kritik konsantrasyonlar esas alınmıştır ${ }^{3}$.

Çalışmamızda Sensititre MycoTB plak yöntemi 14, LJPY ise 42 günde tamamlanmıştır. Lee ve arkadaşlarının yaptığı çalışmada ${ }^{12}$ Sensititre MycoTB plak yönteminde sonuçların alınması için gereken ortalama sürenin 10 gün olduğu saptanmıştır. Çalışmamızda LJPY'de testlerin \%68'i 28 günde sonuçlanmış; ancak yöntem 42. günde tamamlanmıştır. Buna göre, Sensititre MycoTB plak yönteminde testin sonuçlanması için gereken sürenin daha kısa olduğu görülmüştür.

Çalışmamızda Sensititre MycoTB plak yöntemin duyarlıığının \%84.4-100, özgüllüğünün \%95.6-100, yöntemler arasındaki kategorik uyumun ise \%92-100 aralığında olduğu saptanmıştır. Etambutolün en düşük duyarlııı (\%84.4) ve özgüllük (\%95.6) değerlerine sahip ilaç olduğu görülmüştür. Çalışmamızda duyarlılık, en yüksek rifampisin, rifabutin, moksifloksasin, amikasin ve sikloserin (\%100)'de, en düşük etambutol (\%84.4)'de bulunmuştur. İzoniazid, ofloksasin, streptomisin, kanamisin, etionamid ve p-aminosalisilik asidin duyarlılıkları ise sırasıyla \%98.8, \%90.0, \%94.3, \%87.5, \%91.7 ve \%95.6. olarak saptanmıştır. Altın standart APY ile Sensititre MycoTB plak yönteminin karşılaştıııldığı ça- 
Iışmalarda bu oran, Varıcı-Balcı ve arkadaşları ${ }^{10}$ tarafından \%86-100, Hall ve arkadaşları ${ }^{13}$ tarafından \%93.2-100, Xia ve arkadaşları ${ }^{14}$ tarafından \%71.4-100, Lee ve arkadaşları ${ }^{12}$ tarafından ise \%18.2-100 olarak bulunmuştur. Etambutolün duyarılıı̆ını, Yu ve arkadaş|arı ${ }^{11} \% 64.6$, Varıcı-Balcı ve arkadaşları ${ }^{10} \% 88.9$, Xia ve arkadaşları ${ }^{14} \% 100$, Lee ve arkadaşları ${ }^{12} \% 64.3$ olarak bildirmişlerdir. Varıcı-Balcı ve arkadaşları ${ }^{10}$, Sensititre MycoTB plak yönteminde duyarlılığı, birinci seçenek ilaçlar arasında en yüksek izoniazid ve rifampisin (\%100)'de, en düşük etambutol (\%89)'de bulmuşken, ikinci seçenek ilaçlar arasında etionamid (\%86) hariç tümünde $\% 100$ olarak saptamışlardır. Hall ve arkadaşları ${ }^{13}$, duyarlılığı birinci seçenek ilaçlar için en yüksek rifampisin (\%99)'de, en düşük izoniazid (\%93)'de; ikinci seçenek ilaçlar için en yüksek sikloserin, kanamisin ve rifabutin (\%100)'de, en düşük p-aminosalisilik asit (\%94)'te saptamışlardır. Lee ve arkadaşları ${ }^{12}$ yöntemin duyarııı̆ı̆ını en yüksek izoniazid ve ofloksasin (\%100)'de, en düşük sikloserin (\%18)'de bulmuşlardır. Yu ve arkadaşları ${ }^{11}$, bu yöntemin duyarlılığını en yüksek rifampisin (\%98) ve sikloserin (\%100)'de, en düşük etambutol (\%65) ve p-aminosalisilik asit (\%93)'te saptamışlardır. Xia ve arkadaşları ${ }^{14}$ yöntemin duyarlılı̆ını en düşük sikloserin (\%71.4)'de bulmuşlardır. Çalışmamızın duyarlıık bulgularının, Yu ve arkadaşlarııın ${ }^{11}$ etambutol, Lee ve arkadaşlarının ${ }^{12}$ etambutol ve sikloserin, Xia ve arkadaşlarııın ${ }^{14}$ sikloserin için saptadıkları hariç, araştırmacıları ${ }^{10-14}$ verilerine yakın veya aynı olduğu belirlenmiştir.

Çalışmamızda özgüllük etambutol (\%95.6), streptomisin (\%96.9), etionamid (\%97.4) ve p-aminosalisilik asit (\%98.9) hariç diğer ilaçlarda \%100 bulunmuştur. Değişik çalışmalarda araştırmacılar bu oranı sırasıyla \%94.9-100, \%93.2-100, \%79.5-100, \%90-100 ve \%84.3-100 olarak bulduklarını bildirmişlerdir ${ }^{10-14}$. Sensititre MycoTB plak yönteminde saptadığımız özgüllük oranları, Lee ve arkadaşlarııın ${ }^{11}$ etambutol (\%79.5), Xia ve arkadaşlarının ${ }^{14}$ rifabutin (\%84.3) için bildirdikleri hariç, araştırmacıların ${ }^{10-14}$ verilerine uygun bulunmuştur. Duyarlılık ve özgüllükle ilgili araştırmalar arasındaki farklılıklar, izolat sayıları ve ilaç konsantrasyonları ile yöntemsel farklııklardan kaynaklanmış olabilir. Ayrıca kullanılan izolatların direnç özellikleri ve seçilmiş örnekler olmaları da farklıı̆ının bir diğer nedeni olarak değerlendirilmiştir.

Çalışmamızda Sensititre MycoTB plak yönteminin LJPY ile kategorik uyumunun, etambutol (\%92) hariç, \%96-100 aralığında olduğu görülmüştür. Varııı-Balcı ve arkadaşları ${ }^{10}$, Sensititre MycoTB plak yönteminin APY ile uyumunun birinci seçenek anti-TB ilaçlar için \%96-99, ikinci seçenek anti-TB ilaçlar için \%95-100 arasında değiştiğini ifade etmişlerdir. Diğer çalışmalarda Sensititre MycoTB plak yönteminin uyumları, test edilen konsantrasyonlar için sırasıyla \%86.5-99.2, \%79.7-99.1, \%94.3-100 ve \%91.2-100 aralıklarında bulunmuştur ${ }^{11-14}$. Bulgularımızın diğer çalışmalarla uyumlu olduğu değerlendirilmiştii ${ }^{10-14}$.

ÇiD-TB hastalarında tedavi başarısı önemli ölçüde düşüktür. Rifampisin direnci, ÇiDTB varlığının bir göstergesi olarak DSÖ tarafından izlenmektedir ${ }^{1}$. Çalışmamızda sadece rifampisin dirençli suşlar kullanılmış ve 82 izolatın ÇiD-TB olduğu saptanmıştır. Bu verinin DSÖ bildirisinde yer alan tahmini değere (\%79), yakın olduğu düşünülmüştür. Çalışmamızda dört pre-YiD-TB izolatı tespit edilmiş, YiD-TB izolatı ise saptanmamıştır. Ancak uy- 
gun şekilde tedavi edilmeyen hastalarda YID-TB izolatlarının gelişme riski bulunmaktadır. ÇID-TB direncine ek olarak herhangi bir florokinolona veya aminoglikozide karşı direnç olması pre-YID-TB, herhangi bir florokinolona ve aminoglikozide direnç olması ise YiD-TB olarak tanımlanmaktadır. Hastalarda pre-YID-TB/YID-TB izolatının varlığı tedavi başarısı açısından büyük önem taşımaktadır ${ }^{3,5,10}$.

LJPY'de ilaçlı tüpler ayrı ayrı hazırlanmaktadır. Besiyeri ve ilaçlı besiyerlerinin hazırlanmaSı ve kalite kontrolü, zaman alıcı, zahmetli ve özel dikkat gerektiren işlemlerdir ${ }^{15}$. Sensititre MycoTB plak yönteminde, birinci ve ikinci seçenek ilaçların duyarlııkları, aynı anda bakılmakta ve plaklar, hazır liyofilize ilaçlar içermektedir. Gerek APY'de ilaçlı agar plaklarının ${ }^{10}$, gerekse LJPY'de ilaçlı LJ besiyerlerinin ${ }^{8,15}$ raf ömürleri kısıtlı iken Sensititre MycoTB plakları oda sıcaklığında 24 aya kadar saklanabilmektedir. Ayrıca DSÖ tarafından valide edilen LJPY ile sadece duyarlı veya dirençli olarak kalitatif sonuç alınabilirken Sensititre MycoTB plak yöntemi ile antibiyotiklerin MiK konsantrasyonları (kantitatif) elde edilebilmektedir.

Sensititre MycoTB plak yönteminin en önemli dezavantajının, birinci seçenek ilaçlardan pirazinamid duyarlıığının test edilememesi olarak görülmüştür. Ayrıca güncel plak maliyetinin de 470 TL gibi yüksek olması, testin kısıtlayıcı bir faktörü olarak değerlendirilmiştir. Buna karşılık, Sensititre MycoTB plak yönteminin, sonuç alma süresinin kısa olması, duyarlıık, özgüllük ve kategorik uyum oranlarının yüksek olması, birinci ve ikinci seçenek ilaçların birlikte çalışılabilmesi ve ilaçların MiK değerlerinin saptanabilmesi, uygulama kolaylığı, raf ömrünün uzun olması gibi birçok avantaja sahip olduğu değerlendirilmiştir. Bu nedenle, Sensititre MycoTB plak yönteminin, özellikle iş yükünün fazla olduğu laboratuvarlarda, özellikle rifampisine dirençli izolatların anti-TB ilaç duyarlılığının belirlenmesinde kullanılabilecek etkin bir yöntem olduğu sonucuna varılmıştır.

\section{ÇIKAR ÇATIŞMASI}

Yazarlar bu makale ile ilgili herhangi bir çıkar çatışması bildirmemişlerdir.

\section{KAYNAKLAR}

1. World Health Organization. Global tuberculosis report 2018. Geneva, Switzerland: WHO; 2018 https:// www.who.int/tb/publications/global_report/en/

2. Pfyffer GE. Mycobacterium: general characteristics, laboratory detection, and staining procedures, pp: 53669. In: Jorgensen JH, Pfaller MA (eds), Manual of Clinical Microbiology. 2015, $11^{\text {th }}$ ed. American Society for Microbiology Press, Washington DC.

3. World Health Organization. Companion handbook to the WHO guidelines for the programmatic management of drug-resistant tuberculosis. WHO/HTM/TB/2014.11. Geneva, Switzerland: WHO, 2014.

4. World Health Organization. Policy guidance on drug-susceptibility testing (DST) of second-line antituberculosis drugs. WHO/HTM/TB/2008.392 Geneva, Switzerland: WHO, 2008.

5. Tüberküloz Tanı ve Tedavi Rehberi. 2. Baskı. Ankara: T.C. Sağlık Bakanlığı, 2019. http://ekmud.org.tr/files/ uploads/files/tuberkuloz-tani-ve-tedavi-rehberi.pdf

6. World Health Organization. Automated real-time nucleic acid amplification technology for rapid and simultaneous detection of tuberculosis and rifampicin resistance: Xpert MTB/RIF assay for the diagnosis of pulmonary and extrapulmonary TB in adults and children. Policy update. WHO/HTM/TB/2013.16 Geneva, Switzerland: WHO, 2013. 
7. Canetti G, Froman S, Grosset J, Hauduroy P, Langerova M, Mahler HT, et al. Mycobacteria: laboratory methods for testing drug sensitivity and resistance. Bull World Health Organ 1963; 29(5): 565-78.

8. Canetti G, Fox W, Khomenko A, Mahler HT, Menon NK, Mitchison DA, et al. Advances in techniques of testing mycobacterial drug sensitivity, and the use of sensitivity tests in tuberculosis control programmes. Bull World Health Organ 1969; 41(1): 21-43.

9. Clinical and Laboratory Standards Institute. Susceptibility testing of Mycobacteria, Nocardiae and other aerobic Actinomycetes, approved atandard CLSI documents M24. 2018, $3^{\text {rd }}$ ed. Clinical and Laboratory Standards Institute. Wayne, Pennsylvania.

10. Varıcı-Balcı FK, Çavuşoğlu C. Comparison of two methods for the detection of antituberculous drug susceptibility in Mycobacterium tuberculosis complex isolates: sensititre MycoTB MIC plate and the indirect agar proportion methods. Mikrobiyol Bul 2018; 52(2): 123-34.

11. Yu X, Ma YF, Jiang GL, Chen ST, Wang GR, Huang HR. Sensititre MYCOTB MIC plate for drug susceptibility testing of Mycobacterium tuberculosis complex isolates. Int J Tuberc Lung Dis 2016; 20(3): 329-34.

12. Lee J, Armstrong DT, Ssengooba W, Park J, Yu Y, Mumbowa F, et al. Sensititre MycoTB MIC plate for testing Mycobacterium tuberculosis susceptibility to first- and second-line drugs. Antimicrob Agents Chemother 2014; 58(1): 11-8.

13. Hall L, Jude KP, Clark SL, Dionne K, Merson R, Boyer A, et al. Evaluation of the Sensititre MycoTB plate for susceptibility testing of the Mycobacterium tuberculosis complex against first- and second-line agents. J Clin Microbiol 2012; 50(11): 3732-4.

14. Xia H, Zheng Y, Zhao B, van den Hof S, Cobelens F, Zhao Y. Assessment of a 96-well plate assay of quantitative drug susceptibility testing for Mycobacterium tuberculosis complex in China. PLoS One 2017; 12(1): e0169413.

15. Ulusal Tüberküloz Tanı Rehberi (UTTR). T.C. Sağlık Bakanlığı Türkiye Halk Sağlığı Kurumu Başkanlığı Mikrobiyoloji Referans Laboratuvarları Daire Başkanlığı Ankara. Aydoğdu Ofset Matbaacılık, 2014. http:// tb.thsk.gov.tr/UTTR.pdf 